\title{
REDUCED RADIUS OF CURVATURE AND OPTICAL ACTUATION OF NITINOL SHAPE MEMORY ALLOY MEMS ACTUATORS
}

\author{
C. R. Knick, M. D. Srour, and C. J. Morris \\ US Army Research Laboratory, Adelphi, Maryland, USA
}

\section{NOVELTY / PROGRESS CLAIMS}

Through the use of a thinner platinum $(\mathrm{Pt})$ and $\mathrm{NiTi}$, we have achieved a $5.45 \mathrm{X}$ reduction in radius of curvature $\left(\mathrm{R}_{\mathrm{C}}\right)$ for thin film NiTi on Pt actuators that fold flat when heated beyond $60^{\circ} \mathrm{C}$. The radius of curvature reduced from $1.2 \mathrm{~mm}$ [1] to $220 \mu \mathrm{m}$, enabling devices with an overall smaller size. We have also optically actuated devices at $1.44-24.0 \mathrm{~W} / \mathrm{cm}^{2}$, demonstrating actuation times from $4 \mathrm{~ms}$ to $240 \mathrm{~ms}$.

\section{BACKGROUND / STATE OF THE ART}

Sputter-deposited NiTi shape memory alloys are well characterized on a material basis, and several demonstrations of NiTi MEMS cantilevers or actuators have been reported [2]. These devices are variations of sputtered NiTi films on released silicon or other micro machined substrates, where both layers are typically several micrometers or more in thickness [3] ultimately putting a limit on bending radius and range of motion. Cantilever tip deflections in the range of 100's of micrometers for cantilevers several millimeters in length are typical [4].

One reason for the limited selection of substrate materials for MEMS applications is the need to carry out a crystallization step at temperatures of $450^{\circ} \mathrm{C}$ or higher. This anneal step is critical to realizing any shape memory effect, but the fact that significant interdiffusion occurs between NiTi and any substrate material can limit how thin the initial NiTi film may be. Consequently, thicker films are typically used to insure that any interdiffusion layer is an insignificant part of the overall device.

\section{DESCRIPTION OF NEW METHOD / SYSTEM}

Here, we report on the characterization of NiTi films on $\mathrm{Si}$ and Pt layers, with NiTi deposited at $600^{\circ} \mathrm{C}$ at an in-situ crystallization process. We focused on equiatomic $\mathrm{NiTi}$, which thermally transforms between martensite and austenite phases near room temperature, corresponding to significant changes in residual stress, Young's modulus, and other properties that translate into large force and deflection.

Figure 1 shows the process flow used to fabricate the devices which was accomplished via a blanket $\mathrm{Pt}$ evaporation and NiTi co-sputter deposition (Figure 1a) and subsequent lithographic device patterning with a dilute HF wet etch and ion mill for NiTi and Pt films, respectively (Figure 1b). An optional Au electroplate step is possible to help stabilize wider cantilevers and restrict bending to 1 dimension (Figure 1c). We have shown that this step is not necessary when the cantilever width is $\sim 20 \mu \mathrm{m}$ or less. A xenon difluoride $\left(\mathrm{XeF}_{2}\right)$ dry release was performed to release devices from the Si substrate (Figure 1d) where a 5214 mask was used on both the wafer front and backside and a post-release $100{ }^{\circ} \mathrm{C}$ thermal activation was required to set the devices into an upward curl.

\section{RESULTS}

XRD data for NiTi $(270-1600 \mathrm{~nm})$ on $\mathrm{Si}$ in Figure 2 shows that the NiTi has martensite phase present at RT and confirms that the phase change is beyond ambient, which we have confirmed additionally with wafer bow vs $\mathrm{T}$ and DSC measurements (not reported here).

Figure 3 shows the trend in measured and predicted radius of curvature for different $\mathrm{NiTi} / \mathrm{Pt}$ film stacks based on Klein's bimorph model [5]. The model is in excellent agreement for $1.4 \mu \mathrm{m} \mathrm{NiTi}$ on $200 \mathrm{~nm} \mathrm{Pt}$, but $20 \mathrm{~nm} \mathrm{Pt}$ devices deviate significantly from the model prediction. Despite this disagreement, we have obtained devices with very tight $\sim 200 \mu \mathrm{m} \mathrm{R}_{\mathrm{C}}$ using $600 \mathrm{~nm}$ NiTi on $20 \mathrm{~nm}$ Pt.

Figure 4 shows a SEM image of our tightest curled device with $\sim 200 \mu \mathrm{m}$ radius of curvature at room temperature, which is nearly flat above $70^{\circ} \mathrm{C}$ as shown in Figure 5. Figure 6 shows the optical actuation of the $600 \mathrm{~nm}$ NiTi on $20 \mathrm{~nm}$ Pt devices with $200 \mu \mathrm{m} \mathrm{R}_{\mathrm{C}}$ in $\sim 20 \mathrm{~ms}$.

\section{References}

[1] C. R. Knick, M. D. Srour, and C. J. Morris, "Characterization of sputtered nickel-titanium shape memory alloy and microfabricated thermal actuators" in Proc. 29 $9^{\text {th }}$ IEEE International Conference on MEMS, Shanghai, China, Jan. 24-28, 2016, pp. 524-527.

[2] Fu, Y.; Du, H.; Huang, W.; Zhang, S. \& Hu, M. "TiNibased thin films in MEMS applications: a review," Sensors and Actuators A: Physical, 2004, 112, 395-408

[3] W.M. Huang, Q.Y. Liu, L.M. He, and J.H. Yeo. Micro NiTi-Si cantilever with three stable positions. Sensors and Actuators A: Physical, 114(1):118 - 122, 2004.

[4] Fu, Y. et al. "Characterization of TiNi shape-memory alloy thin films for MEMS applications" Surface and Coatings Technology, 2001, 145, 107-112

[5] Klein, C., Miller R., "Strains and stresses in multilayered elastic structures: The case of chemically vapor-deposited $\mathrm{ZnS} / \mathrm{ZnSe}$ laminates," Journal of Applied Physics, vol. 87, no. 5, pp. 2265-2272, 2000. 
A.

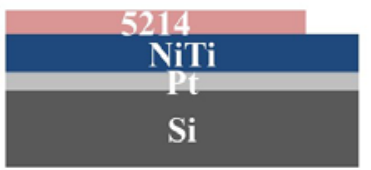

B.

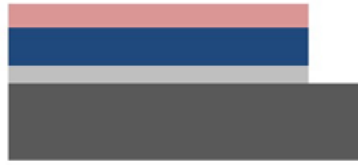

C. (optional)

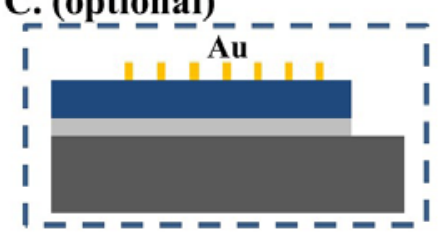

Figure 1: Process flow for NiTi on Pt MEMS SMA actuators with dry release

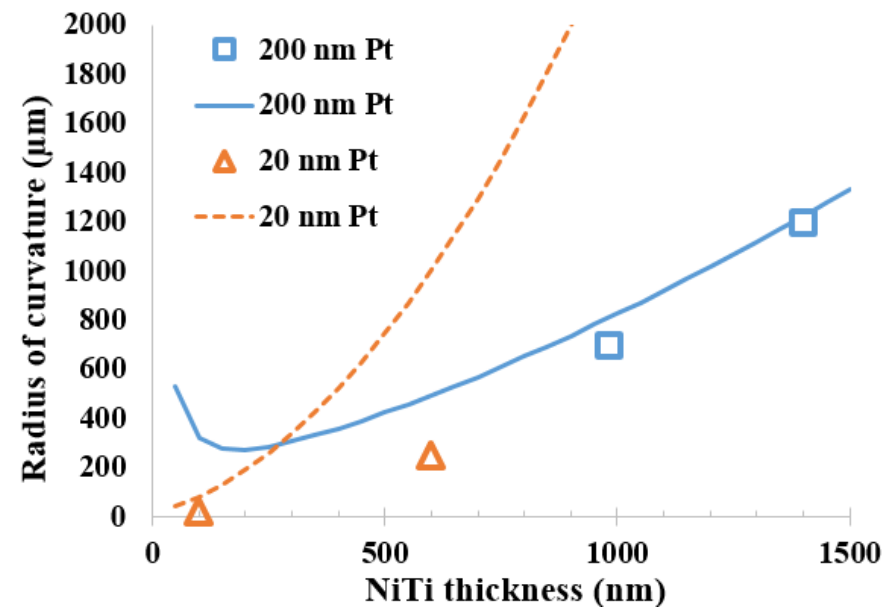

Figure 3: Predicted (solid and dashed lines) and measured (symbols) radius of curvature $R_{C} v$ v. NiTi thickness for $20 \mathrm{~nm}$ and $200 \mathrm{~nm}$ Pt bimorphs

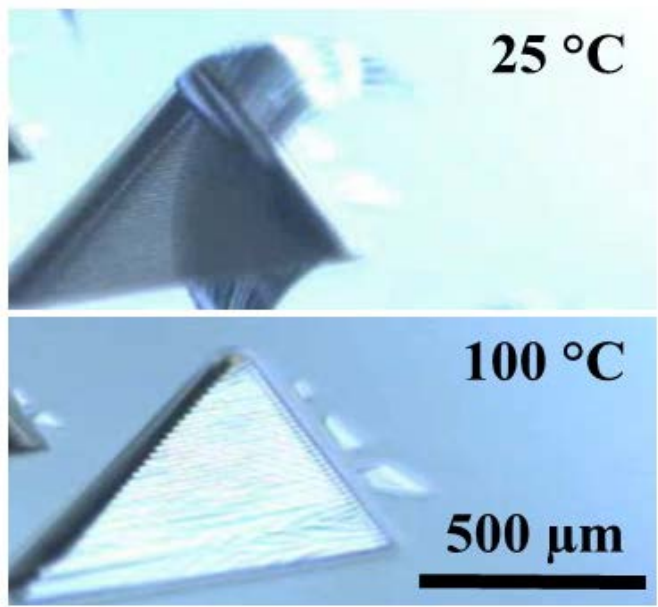

Figure 5: Thermal activation of $600 \mathrm{~nm}$ NiTi on $20 \mathrm{~nm} P t$ devices between tightly curled at RT and flat at $100^{\circ} \mathrm{C}$

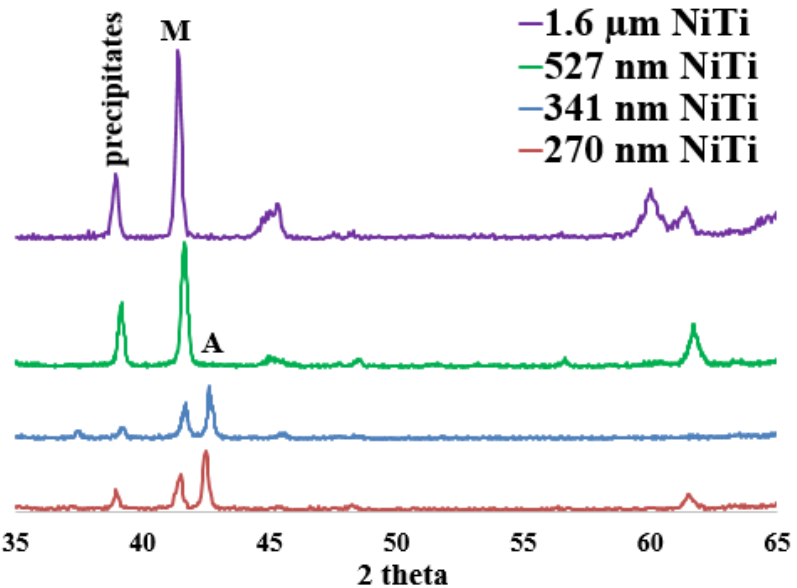

Figure 2: XRD spectra for various NiTi thickness on $\mathrm{Si}$ confirming martensitic phase at $R T$

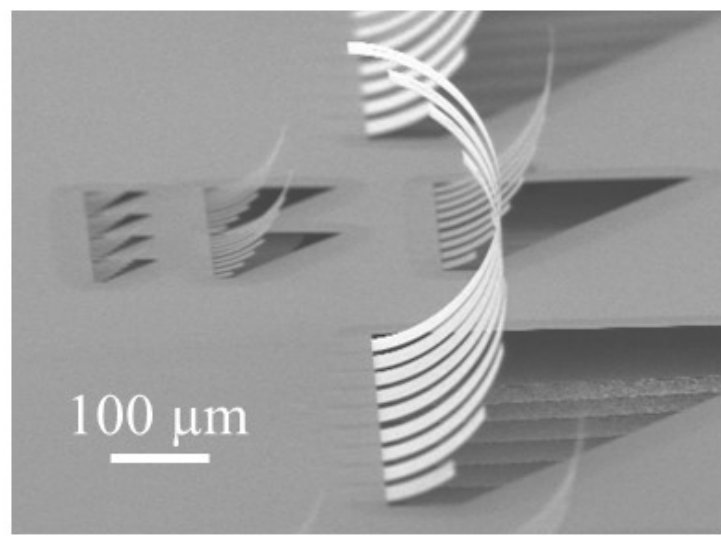

Figure 4: SEM image of released and thermally activated $600 \mathrm{~nm}$ NiTi on $20 \mathrm{~nm}$ Pt devices with thinnest reported radius of curvature of $\sim 200 \mu \mathrm{m}$
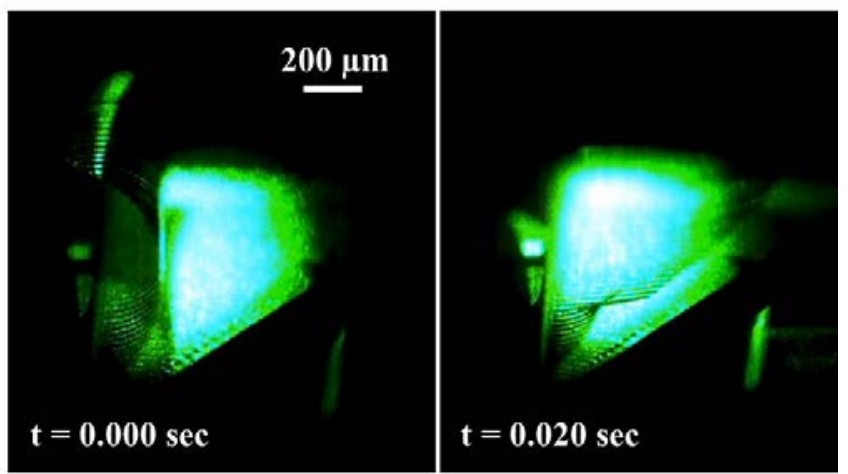

Figure 6: Video frames showing optical actuation of a cantilever array of $600 \mathrm{~nm}$ NiTi on $20 \mathrm{~nm}$ Pt using a $532 \mathrm{~nm}, 440 \mathrm{~mW}$ laser with intensity of $6 \mathrm{~W} / \mathrm{cm}^{2}$. 